\section{Deep pockets}

\section{Critics should give the first head of Britain's new science mega-funder a chance.}

$\mathrm{M}$ ark Walport is not a man to mince his words, but he has no doubt developed his diplomatic skills during his three years as chief scientific adviser to the UK government. Those skills are already being tested as he prepares for a sideways move to what is arguably the most important job in UK science. As the government announced last week, Walport - former director of the Wellcome Trust, Britain's biggest biomedical charity - is to be the first head of a powerful new funding body called UK Research and Innovation (UKRI).

Given the enormous $£ 6$-billion (US\$7.4-billion) annual budget he will have at his disposal, and the political upheaval of the restructuring of the UK funding landscape, his appointment has sparked much chatter among policy watchers. Some critics take aim at his perceived tendency to centralize power. And during his time as chief scientific adviser, bureaucratic wheels were put in motion that prompted the ongoing reshuffle of UK science - combining the autonomous research councils that distribute government cash to scientists.

The appointment deserves scrutiny, but Walport equally deserves his chance to show his critics what he can do. He has been a powerful and visible figure as chief scientific adviser, and is undoubtedly one of the UK scientists best qualified for the role. In an interview with Nature and in other public statements following his appointment, Walport has tried hard to make the right noises, for example by emphasizing the continuing importance of the nine research funders brought into the fold of UKRI under his imminent leadership (see Nature http://dx.doi. org/10.1038/nature.2017.21441;2017).

It will be crucial for the health of UK science that he does so, and that he enables British science to truly speak with "a single voice", as he puts it. And he is correct to say that, on the face of it, the UKRI board and the institute's executive now provide an extra link in the chain between the research councils and the Department for Business, Energy and Industrial Strategy and its ministers. Whether that extra

distance from ministers reinforces independence will depend on the new chief executive of UKRI, and there is every reason to think that Walport can support that essential detachment.

It is also important that Walport and UKRI carefully balance the attention and support given to science and to innovation. Despite his history of support for large-scale initiatives in the life sciences, he and his funding bodies must also continue to appreciate the value of small-

"Walport's years of working for government give him contacts and insights." scale laboratories across all disciplines.

The creation of UKRI has not yet been approved by Parliament, and its formation has been controversial. As well as anxiety over consolidation of the previously independent research councils, there are fears about the potential for increased government interference in bodies that currently make most of their own decisions on how to award funding.

And all this comes while British scientists are waiting to see how the country's departure from the European Union will affect them and their work. Scientific leaders and universities were among the most vocal supporters of the losing Remain camp, and the international nature of research makes it vulnerable to the uncertainty and upheaval that the decision is causing. Spirits have been raised a little by the government's November 2016 announcement of extra funding for research, planned to reach $£ 2$ billion per year by 2020 . That was unexpected, but insiders say that it would never have happened without the new structures being put in place. For example, some of this money will go towards collaborations between science and business that will be overseen by a new fund modelled on DARPA, the US defence department's research arm.

Walport is certainly a strong leader, and UKRI will bear his imprint. His statements about autonomy and the need for strong leadership of the research councils after they are subsumed by UKRI are welcome. Appointments of strong, independent-minded board members by ministers will also go some way to allaying concerns about the centralization of such power and influence in one person. Walport's years of working for government also give him contacts and insights that only a few other candidates might boast. These will be needed more than ever as UK scientists are battered by the stormy waters of Brexit.

For some scientists, Walport's proximity to the heart of government is uncomfortable. But this experience, wielded wisely, will work in his favour. -

\section{Monster plants}

\section{Carnivorous plants have fascinated writers and botanists alike.}

A lesser-known mystery by the creator of Sherlock Holmes concerns the fate of a man called Joe 'Alabama' Hawkins. Hawkins has vanished and is presumed murdered; a man is set to hang for his murder before Hawkins rolls, half-digested, from the leaf of a giant Venus flytrap.

'The American's Tale' by Arthur Conan Doyle was one of a crop of monster-plant stories that started to appear towards the end of the nineteenth century - a literary genre that climaxed decades later with The Day of the Triffids by John Wyndham. Arguably, it started with an 1875 work of non-fiction: Insectivorous Plants by a certain Charles Darwin. Scholars of monsters in fables and literature, and there are more than you might think, point out that man-eating plants (unlike, say, vampires, werewolves, zombies and dragons) were unheard of until Darwin's book seeded the idea in the imagination.

The flytraps of Doyle's story were unfeasibly big, but they were also in the wrong place. Despite the name, 'Alabama' Hawkins met his end as flytrap mulch in the Flytrap Gulch in Montana. And, in the real world, Venus flytraps (Dionaea muscipula) don't grow in Montana. Native Venus flytraps, in fact, don't grow anywhere in the wild except in boggy soil within 100 kilometres or so of Wilmington, North Carolina, on the eastern coast of the United States. That rare population is under such threat from poachers that it is now a felony to remove one of the plants: the first person to be imprisoned under the new law began his sentence last year. (The penalty used to be a US $\$ 50$ fine and a slap on the wrist.)

There are many other species of carnivorous plant worldwide. And in a study released this week (K. Fukushima et al. Nature Ecol. Evol. 1, 0059; 2017), researchers describe how these meat-eating plants rely on much the same genetic recipe, even though the different groups evolved the habit of carnivory quite independently. All were after the same thing: nutrients such as nitrogen and phosphorus that they couldn't extract from the meagre soil.

Some scientists argue that there are more carnivorous plants than is generally accepted (M. W. Chase et al. Bot. J. Linn. Soc. 161, 329-356; 2009). The Venus flytrap and the rest, they say, are merely the most active and open meat-eaters. Others are more subtle, and have evolved to trap flies that are then just left to decompose and leach their lifeblood into the surrounding soil, within reach of hungry roots. Among these hidden carnivores, they say, are the humble potato and even that garden favourite, the petunia. Be afraid, but not very. 